\title{
El viaje del Conde de Lemos desde Porto-Belo al Callao.
}

\section{(ESTAIVIPA DEL SIGLO XVII)}

El. Conde en Porto-Belo.-Propone el ataque

$$
\text { - a Tamaica }
$$

Es de suponer que a su paso por Porto-Belo, el Conde de Lemos no se preocupara mucho de la feria. Otras inquietudes le acapararone.En primer-lhgar, y en esto fué muy previsor, lēoinquietócilae cercaníarscdel enemigo inglés. Habían, en efecto, los ingleses, ocupado Jamaica en I655. Con este acontecimiento inauguraron un nuevo período en la historia americana, pues fué aquélla la primera vez que los extranjeros se anexaban de modo permanente un sector del territorio descubierto y colonizado por España.

No se resignaba Lemos a la vecindad de los enemigos que-entre ingleses y franceses-además de Jamaica, 1legaron a poseer Barbados, San Cristóbal, la parte norte de Santo Domingo y otras islas más pequeñas. Propuso Lemos la recuperación de Jamaica, para lo cual remitió la planta de dicha isla, así como el medio y forma para el logro de tal proyecto. También representó acerca de la necesidad de 


\section{$-6-$}

una armada en las costas de Barlovento para preservarlas de corsarios; armada que, por lo menos, debía constar de ocho fragatas de hasta 20 cañones (I).

No se tomaron en cuenta estos consejos; pero la experiencia demostró bien pronto su cordura.

De Porto belo pasó el Conde de Lemos, de acuerdo con sus instrucciones y con la costumbre de sus predecesores a Panamá.

\section{Viaje de P'orto Belo a PANamá}

El viaje de Porto Belo a Panama era hecho, cuando se trataba de personajes de viso, en embarcaciones a remo, o en pequeños velcros. Descmbarcaban los pasajeros en la boca del rio Chagre, doncle estaba ch castillo de ese nombre; y subian el rio a remo, hasta/legar al puerto de Cruces que era el desembarcadero, a poco más de cinco leguas de l'anamá. En el río veíase merodear a los lagartos o caimanes; y. hasta las orillas llegaban los árboles silvestres de sin igual espesura, mostrando su incréble abundancia de monos y de aves. Algurols patajos ded rio, dtamazlos "raudales", estaban casi secos y alli era precisg avanzar cargando las embarcaciones hastá encontrar sitios con mas fondo. Los bosques frondosos; las densas colinas; las cuadrillas de monos saltando de unos a otros árboles colgados de las rainas y encadenados seis, ocho o más, con incesantes gestos y visajes; las aves abundantes y de especies curiosísimas; los múltiples colores y sonidos de aquel paisaje orfeónico y abigarrado, impedian la monotonía del viaje y compensaban los calores que, sobre todo para la gente blanca recién llegada, eran enervantes.

(1) Dos eartas del Conde de Lemos desde Porto Belo, 7 de Junio de $\overline{1667 .}$ Audiencia de Lima, legajo No. 56. Repite su coutonido en la de 1 de Mayo de 1669 que está en "Contaduría" númere 32. 


\section{$-7-$}

Después de desembarcar en Cruces, bodega y aduana de mercaderías, la marcha se hacía por tierra desde ese lugar hasta Panamá, durando desde la mañana hasta la caicla de la tarde.

\section{El chogue con Pérez de Guzmán}

De la estancia del Conde de Lemos en Porto Belo y su viaje a Panamá resultó otro hecho, mucho más sonado, que en verdad vino a ser $u 1 n$ acontecimiento sin paralelo.

Gobernaba Panamá y su distrito como Presidente y Capitán General, D. Juan Pérez de Guzmán. Este personaje había entrado en abierta desayenencia con los oidores de 1a Audiencia, así como también con los oficiales reales de dicha ciudad. A favor de Pérez de Guzmán estaba, en cambio, el fiscal de la Audiencia D. Alonso Cajal y del Campo. Las desavenencias habian llegado a manifestarse en graves sucesos, desde que un dia ananeció en uno de los pilares de la plaza un papel sin firma titulado "Aviso al Gobernador" denunciandelque Qos eficiales reales tramaban su envenenamiento. Comrtad Ruotivoelsécabrióruna información y fueron apresados el contador D. Sebastián Gómez Carrillo y el tesorero D. Juan de la Valera Pizarro. Pérez de Guzmán nombró un contador interino para que no cesara el despacho de la Caja Real. Casi al mismo tiempo renunció el cargo, diciéndose rodeado de calumnias y falsedades "como todo hombre de bien cristiano y celoso de que se administre justicia en Indias" (2).

Cuando el Conde de Lemos 1legó a Porto Belo, dió comisión al oidor de la Audiencia de Lima D. Lope Antonio de Munibe que con él había hecho el viaje, para que averi-

(2) Renuncia fechada el 22 de oetubre de 1666. A. de I. Audiencia de Panamá, legajo No. 93 . 
guase qué personas habian introducido plata de la del l'erú sin registrar ni pagar la contribución que daba el comercio. Munibe empezó a dar cumplimiento a esta comisión en Porto Belo y la acabó en Panamá (3). Examino once testigos y halló 36 barras que no cran del rey y se entendia haberse introducido por medio de D. Francisco Teran de los Rios, el contador interino nombrado por Pérez de Curmán. Terán, por su parte, alegri haberlas comprado en Panami para S. M.; pero quedó preso y con sus bienes embargados.

Ia enemiga de Lemos iba en realiriarl contra Pérez de Guzmán. Ya el nidor mis antiguo D. Bernardo Trigo de Figueroa había cuidado de ponerse en relacion con él por carta y Trigo era uno de los más implacables enemigos del irascible Presidente de Panamá. También intrigó activamente contra éste el contador Gómez Carrillo, preso aún, que se valio del religioso mercenario Fr. Francisco de Ouirós para lograr cartas de prelados a su favor. Otros testimonios más escuchó en el mismo sentido el conde en Porto Belo. Escribió descle ese pucrto a Pérez de Guzmin para que dejara en libertad a bos oficiates feales Gómez Carri11 y Vera PizanogeyP Pérez de Guznên replicó que esa era materia muy grave por ser ambos oficiales ladrones consumados. Insistió el virrey y volvió a negarse el Presidente de Panamá, alegando que si la potestad dada a él por S. M. con el bastón de mando había cesado, dicha orden de libertad podría ser cumplicla; pero que mientras tuviese el bastón, nó lo consentiría y se dejaría "cortar la cabeza (4). Eso era demasiado para un hombre del temple de Lemos, (3) Proceso empezado el 11 de junio de 1667. A. de I. Audiencia de Pa-
namá, legajo N\$. 93. (4) Carta de Pérez de Guzmán narrando estos hechos, Porto Belo, 2 do
julio de 1667. Audiencia de Panamí, legajo 93. Dice D. Antonio Ruiz de
Alarcón en su informe al rey citado mís aldante que To Alarcón on su informe al rey citado más adelante que Lemos pidió además
los autos y que P. de G. los nego, exclamando entonees Lemos (según se di-
jo): "Poca necesidad tengo de pedir cuando tengo poder jo): "Poca necesidad tengo de pedir cuando tengo poder para mandar". 
imbuído, además, de la importancia adicional que le confería su flamante cargo de virrey.

Treinta días se quedó el conde en Porto Belo y al fin emprendió su viaje a Panamá. Antes de él, obtuvo del comercio de aquella ciudad, con presión, 450,00o pesos para sus gastos. De Porto Belo a Panamá pasó más de I,ooo cargas de ropa, cantidad que pareció excesiva a sus enemigos, en cuanto al costo de ese traslado.

En Panamá se alojó el conde en casa de D. Bernardo Trigo, no queriendo ir a la que Pérez de Guzmán tenía "colgada y aderezada".

Apenas llegado a Panamá pasó a hacer el conde la visita de cárcel con los miembros de la Audiencia. Entre los presos halló a los tres ingleses que se rindieron en la isla de Santa Catalina a los cuales se les había dado cuartel y palabra de guerra. Además, había, a juicio del conde, daño en que los extranjeros estuvieran tanto tiempo en Indias, por los datos que podían recoger y el daño que podían causar si volvían donde los suyos. Por todo ello dió auto para pasarlos a Porto Belo y entregartos al generat de la armada, con destino a la Cosa de Contratación. Sin enbargo, cuando llegaron a Porto Belo, Pérez de Guzmán los hizo apresar en el castillo de Santiago. Lemos dió orden entonces para que fuesen enviados a La Habana y para que el gobernador de esa ciudad los entregara al general de galeones (5).

Nuevas y peores quejas recibió Lemos en Panamá de los descontentos y resentidos con Pérez de Guzmán. Proveyó un auto, con consulta de la Audiencia, para que se averiguase dichas quejas. Examinó inmediatamente después hasta 32 testigos y descubrió o creyó descubrir contravenciones, en daño de los ramos de hacienda, justicia, gobier-

(5) Carta de Lemos, Panamá, 28 de julio de 1669; A. de I. Audiencia de Panamá, legajo No. 93. 
no y guerra. Más positivos quc los latrocinios eran seguramente los actos de arbitrariedad, violencia y descortesia cometidos por Pérez Guzmán. I)ijérase que la perspectiva del veneno habiale hechos concter desatinos. Habia mandado poner en su casa piezas de artilleria cargarlas con balas, abocindolas a la ciudad, con prevención re soldados y artilleros: y tenía la sala de su vivienda llena de carabinas, escopetas, pistolas largas, montantes y esparlas. Gala habia hecho de su carácter intemperante. Tos regidores o "a'cin" ticuatros" de la ciudad alegaban tener privilegios de decurinnes $y$ no querian mezclarse en marchas y reseñas, creyéndose obligados a estan cerca de la persona del Capitín General y la custodia Adel estandarte real. Pérez de Guzmán. sin embargo, los sncó "entre nogros y mulatos, en latalla", agravio por el cual protestaton con indignación (6). E1 mismo Pérez de fitzmin sabia que sus enemigos eran muchos. Ya se ha vistd rue habia presentado su renuncia. "Me aborrecen de calidad", escribía en pleno proceso, insistiendo en stBempeño de rejar el mando ( 7 ).

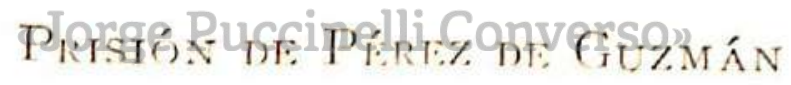

El virrey sacó de sus prisiones a Gomez Carrillo y Vera Pizarro, hecho que acabó de excitar a Pérez de Guzmán ya que según él, ambos oficiales reales tenian negras hechiceras en su casas y le envenenarían. A quien envenenaban en esos momentos era al virrey, no sólo los oficiales reales sino varias otras personas, entre las que se contaban los oidores, el letrado Sebastián de Velasco, un escribano de cámara 1lamado D. Gabriel Martínez de Salas, un tal Pedro de Segu-

(6) C'abeza de proceso, Panamá, 5 de julio de 1667. Legajo citalo de 1: Audiencia de Tanamá. Carta del Cabildo, 2 de agosto ie 1667 , contra Pérez de Guzmán. Legajo citado.

(7) Carta de Pérez de Guzmán, 14 de julio de 1667. Logajo citado. 
ra que ejercía el cargo de proveedor, además de Pedro de Arredondo en Porto Belo y Juan Gómez Carrillo que acababa de llegar. En cambio, el virrey no escuchó ni una vez siquiera a Pérez de Guzmán, ni aún para preguntarle porqué aquellos sujetos eran enemigos suyos ( 8 ).

Después de recibir a todos los testigos, reunió el virrey a los oidores de Panamá, al oidor de Lima, Munibe, y al obispo de La Paz Fr. Martín de Montalvo, ya que el de la ciudad no estaba alli, si bien más tarde remitió su parecer solidario. Consultados estos personajes, unánimemente declararon que, en vista de lo averiguado, no sólo podia sino también debía el virrey suspender a Pérez de Guzmán en su oficio, prenderlo y embargar sus bienes. Pérez de Guzmán se había retirado el $\&$ de julio al castillo de Santiago de Porto Belo, con el fiseálde la Audiencia, Cajal, el contador Terán y la gente pagada que estaba en Panamá por ocasión de galeones con su capitán Juan Giménez, la cual recibió dos pagas. Hizo a su vez, Pérez de Guzmán en Porto Belo una junta, con D. Juan Cornejo, visitador del virreinato del Peirúlqué eregresabā atEspaña, el fiscal, el general de la armada, $\mathrm{y}_{\text {u }}$ otros $j$ pficjales de ella, más los castellanos de San Fehpe y Santiago. Las siguientes cuestiones fueron presentadas por Pérez de Guzmán: I. ¿ Tenía el virrey facultad para suspender al Presidente de Panamá? 2. ¿ Sí el virrey nombraba nuevo Presidente, a quién obedecerían los castellanos y demás cabos de Porto Belo? 3. ¿Convenía que Pérez de Guzmán se embarcara en los galeones o que se quedara? La resolución adoptada fué unánime y gravísima: I. El virrey no podía hacer la destitución, sin orden de S. M. 2. El Presidente de Panamá era el capitán general de los castillos. 3. El Presidente no debía embarcarse en los galeones.

(8) Carta del mismo, 9 de julio. Legajo citado. 
Y se quedó en el castillo de Santiago. El príncipe de Montesarcho le dejó treinta hombres. Ordenes ratificando su autoridad fueron enviadas a Chagres, a Villa, a Nata y a Panamá.

E1 virrey pensí que si de ese modo obraba Pérez de Guzmán con sus superiores, cómo obraría con sus súbditos. E1 14 de julio proveyó un auto suspendiendole y mandíndole prender y embargar sus bienes, dilatando su publicación hasta el i6. Por compasión de que se perdiera "un caballero de calidad", le escribic advirtiendole el crror y lit responsabilidad de tratar de resistir. Invocó la cédula de 2 r de octubre del año anterior por la cual el gobierno superior de Panamá quedaba incorporado al del Perí (como estatuía la ley $5 .{ }^{a}$, libro 4 , titulo 3 ). La Tey ${ }^{n}$ y título 15 del mismo libro decía por otra pafte cue en Tierra Firme se guardara lo que el virrey del Berí proveyese; y la ley i 7, capítulo 3 del libro mencionado agtegala que cuando el virrey del Perú pasara por Panamáo viajara a Quito, podia proveer en asuntos de gobierno.

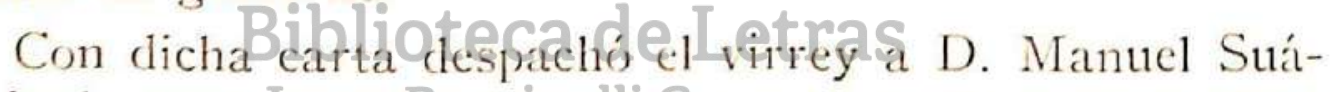

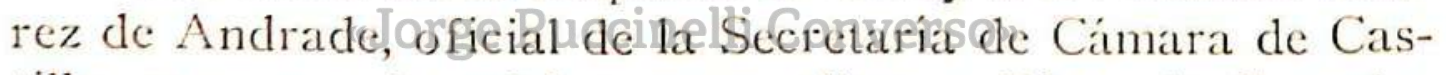
tilla, para que de palabra persuadiese a Pérez de Guzmán. Al castellano D. Juan de Somovilla debía entregar además Suárez de Andrade una orden para que prendiera a Pérez de Guzmán si se resistía; y al alcalde mayor y al Cabildo, otra orden para que publicara, so pena de inobediencia, la suspensión del desventurado Presidente. La publicación hecha en Panamá de dicha decisión provocó "vítores", "como los de los doctores de Salamanca", dice Lemos. E1 Cabildo eclesiástico cantó con música el "te deum laudamus". E1 Cabildo secular puso un "vitor" en la puerta de la casa del virrey, con letras de oro, llamándole "restaurador de la República"; pero el virrey lo hizo quitar apenas lo vió "por- 
que donde yo estuviere no se ha de vitorear a nadie más que el Rey". En las casas de casi todos los vecinos fueron colocadas luminarias; y unos a otros se daban enhorabuenas. Al deán de la iglesia y a los superiores de los conventos escribió el virrey para que con este motivo descubrieran durante tres días el Santísimo Sacramento, celebrándose el primer dia misa votiva a la Trinidad, el segundo al Santísimo Sacramento, y el tercero a la Purísima Concepción. El virrey asistió los tres días. No olvidó, según propia confesión, la discreta sentencia de su abuelo San Francisco: "Dios como si no hubicse medios y medios como si no hubicse Dios". Hizo embarcar cien infantes de la Armada y puso por cabo de ellos a D. Antonio Ordoñez del Aguila, caballero del hábito de Santiago, mandándolos a Porto Belo y disponiéndose a ir él luego personalmente con el grueso de la gente.

Pérez de Guzmán primero se excusó de ir donde el virrey, con certificado de médico; pero sabiendo los preparativos que se hacían, obedeció. Se vió, como dijo al general de la armada del Suretcogidoden ratonera. Quedó preso en la casa del Cabildo dePRanamả lyc de Real Almiranta de la armada del Sur para viajar al Callao. Contra el fiscal D. Alonso Cajal, acusado también de defraudación, dejó el virrey auto para que D. Bernardo Trigo lo examinara, por ser preciso su viaje al Perú. Como Presidente interino de Panamá quedó D. Agustín de Bracamonte..

Rehabilitación posterior de Pérez de Guzmán.Castigos al conde

El Consejo de Indias tomó cuidadosa nota de todos los papeles que llegaron concernientes a estos sucesos. Un Relator hizo la ordenación de ellos y su examen duró dos días. 
El Consejo fué, al fin, de parecer, por unanimidad, de que el Conde de Lemos habia procedido contra D). Juan L'erez de Guzmán sin ninguna jurisdicción. Como virrey recien nombrado, no la tenia contenciosa hasta que no entrara en la ciudad de Lima, cabeza del gobierno, y tomara posesion de el, jurando en la forma ritual. Esa era la norma de derecho, aún para resoluciones de menor gravedad. Este asunto debió ponerlo en manos de S. M., dando cuenta, sin ejecutar su decisión tan apresuradamente. El uso y ejercicio del cargo que se le habia cometido no comenzaba ni podia comenzar para semejantes causas y casos hasta haber cesado el gobierno de la Audiencia de Lima. Sus actos habian sido, pués, un atentado. Jurídicamente, eran nulos. D. Juan Pérez de Guzmán habia quedado ofendido en su reputacion y en su honor. No sólo había actuado para ello el Conde de Lemos con falta de juriscliecion; sino que la sustanciación de la causa no habia sido legitima pués debió tomarle confesión y oirle en juicio abierto. El Consejo agregaba todavía: "No ha causado poco reparo ver que siendo tan ajeno del Conde de Beimoşopese peronat dignidad y grado y tan diverso de su profesiónccualguicrivegatienda judicial, examinase por sí mismo los testigos, cosa muy inaudita". Por último, no existía culpa que mereciera tan grave castigo, pues las inculpaciones eran de oídas, y si habían comprobaciones no eran de gran sustancia; lo único que se sacaba en claro era que Pérez de Guzmán había obrado a veces arbitrariamente.

Por todo ello, el Consejo dió su parecer, en el sentido de que debía procederse a lo siguiente: I. Libertad, desembargo de bienes y restitución de Pérez de Guzmán a su cargo en Panamá. Interin éste volvía, no debía continuar en la Presidencia de Panamá D. Agustín de Bracamonte, nombrado por el Conde de Lemos, ilustre por su sangre, 
pero demasiado mozo y bisoño para un cargo que requería persona militar y de experiencia. 2. Pago por el Conde de Lemos de los gastos de viaje, prisión, regreso y costas de D. Juan Pérez de Guzmán. Los salarios percibidos por Bracamonte debía pagarlos, asi mismo el conde. Los oficiales reales de Lima debían descontar todo este dinero y remitith a España.

El virrey recibió, además, una prevención especial para que se contuviera dentro de los límites de su título, su instrucción y de lo dispuesto en las ordenanzas de las Audiencias de su gobierno.

Los consejeros y colaboradores del conde recibieron multas y reprensiones. D. Bernardo Trigo fué llamado a España, lo cual satisfacía sus propios deseos. Ya en tiempo de D. Fernando de Riva-Agüicro se había hecho venir a Gómez Carrillo y demás oficiales reales de Panamá, pero como era conveniente la presencia de persona de experiencia para el despacho de galeones y remisión de tesoros, se suspendió; ahora, pạdehnés dexondeñársele en 4,400 pesos, se dispuso que viajara a Españal cuanto antes (9).

Por cédula de 26 de junio de 1668 ordenó la Reina que cl Conde de Lemos entregara de su sueldo a D. Juan Pérez

(9) Ver las cartas del conde de Lemos de 22 de julio y 5 de agosto de 1667. Igualmente, el resumen de los sueesos hecho por el relator del Consejo de. Indias y la resolución de éste, el 14 de enero de 1668 . Toto en el A. de I.,

Los cargos contra Pérez de Guzmán habían sido en resumen: 10. Indulto para el passije de la plata blanea, sin quintar, de la armada de 1665 , reeibiendo 25,000 pesos de los interesados; 2o. Recaudación de los derechos de aleabalas y correduría de dicha armata, con mucho fraude y sacando 41,000 pesos para sí; 3o. Aprovechamiento en lo procedido del derecho de botijas de vino que venían del Perú y en la imposición de un tributo para aderezos do caminos; 4o. Indulto do la plata blanea en la última armada; 5o. Revocación por soborno, del nombramiento hecho por el comereio de Lima en la causa de los diputados de dieho comercio; 6o. Colocación por dinero de Franciseo de Herrera en el castillo de Chagres y mantenimiento de Agustín de la Concha en la tenciurín de bastimentos, por la misma causa; 70. Dación de oficios y plazas a parientes y criados que no los servían pero cobraban; So. Conducta áspera, descortés y hasta irreverente con obispos, oidores religiosos y otras personas. 
de Guzmán ocho mil pesos que era lo computado por los gastos de su forzado viaje de Panamá al Callao; y que le diera embarcación adecuada para que cuanto antes pasara a servir otra vez la Presidencia de Panamí. Ademas, debia enviar cuenta a parte de lo que importara el salario devengado por D. Agustin de Bracamonte que habia quedado como Presidente interino.

A la llegada del "aviso" con los despachos reales se juntaban de seis a ocho de la noche el virrey, los oidores, los alcaldes de crimen, los contadores y los oficiales reales, con el secretario de Cámara. La orden acerca de Pérez de Cinzmán fué abierta a las acholde la noche; y a las ocho de la mañana siguiente renitió el eonde los ocho mil pesos a $P$ érez de Guzmán, con un permiso para que escogiera una cmbarcación y cuantorantes rajara, no obstante estar cerrado el puerto por ser tienpo de armada. La orden real hablaba de la intervención de los oidores y ofjciales reales. El virrey, al dar cuenta de todo esto con los recibos y certificados pertinentes alegó que tanta precaución era innecesaria, pues "para et Cende décemos basta aualquiera insinuación de la real voliontga PidecSnelli panaecjecontarla, aunque sca contra si". (IO).

Viaje de Panamá al Callao. Fisonomía de la costa NOR-PERUANA A MEDIADOS DEL. SIGLO XVII

La Armada del Sur salió de Panamá el 5 de Agosto de 1667 llevando al Conde de Lemos, a su comitiva y al prisionero D. Juan Pérez de Guzmán. Llegó a Paita el I4 de setiembre. La navegación reiteró la monotonía del largo via-

(10) Carta del conde de Lemos, de 10 de enero de 1669 . A. de I. Aulien. cia de Lima, legajo 68. ("I)uplicarlos de los despachos más principales que fueron en el aviso que salió del Callao a 30 de enero de 1669 y en la armada que partió a 23 de marzo del mismo año"). 
je marítimo anterior. Tuvo ella solamente dos notas distintivas: una tempestad que se desencadenó poco después de salir de Panamá y que hizo daños a la nao donde iba cautivo Pérez de Guzmán y las misas y demás ceremonias religiosas a que se dedicaban el virrey y su familia, para asombro de los tripulantes ( 1 I ).

Era la de Paita comarca sana pero seca y tanto que el agua llevaba a ese puerto desde el río de Colán, distante tres leguas. En Paita se detuvo el Conde de Lemos doce días, con el objeto de recibir los bastimentos, aguada para seguir su derrota. Estando en Paita, llegó a su poder la relación que la Audiencia de Lima le dirigiera acerca de los juramentos que los virreyes debian recibir de las Audiencias, tribunales, prelados, cabildos y personas particulares, junto con algunos papeles relativos a la administración del Virreinato. A don Jacinto Romero de Caamaño, gentilhombre de cámara, despachó entonces el Conde de Lemos como embajador para avisar a la Audiencia su llegada a Paita y para solicitar, de acuerdo con las reales cédulas del caso, una relación sobre el estado de los negocios públicos.

La entrada deo RomenciCabnañovensLima tuvo lugar el domingo 23 de octubre a las cinco de la tarde y los oidores lo recibieron en la sala del Acuerdo, fuera el sitial v quitada la mesa. "Le dieron asiento al embajador junto al Presidente, donde hizo larga relación del señor Virrey, de sus padres y agüelos y de toda su prosapia con lindo despejo. Y le aposentó el señor oidor D. Bernardo de Iturrizarra junto a su casa, en la plazuela de San Diego, y le acompañó to-

(11) “Carta del Capitín Don Manuel Coello, Sargento Mayor de la gente de guerra que llevó el Conde de Lemos, virrey del Perú, para la pacifieación de las provincias le Puno, escrita a un su correspondiente de la ciudad de Cadiz, con relación del viaje y sucesos" 1667-1671. Biblioteca Nacional de Madrid. Ms No. 11017. (En realidad, no sólo trata de dicho asunto sino de los princinales ameesos del gobierno del Conde de Lemos desde la salida
de Panamá). 
do el regimiento y torla la caballeria desta cindad" (12). Inmediatamente despues de sn Heradal. Romern de (a)maño fué nombrado por la Audiencia corregirlor de la prosincia de Collucos, "en fe de qute serí del servicin y asmarlo de V. E. y de su presunta licencia" secein dijeron aduladoramente los oidores en su "Relacionn" (

El virrey continuó su viaje a bordo. a pesar de lo penoso que él resultaba: y es que no queria wozar de las como-

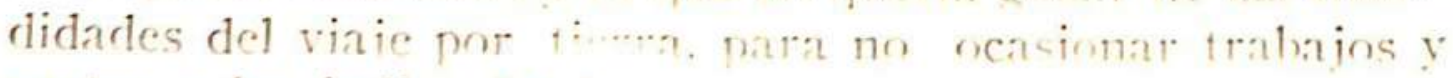
gastos a los indios (I4).

Aquel seguía siendo un mundo nuevo para el conde. bien distinto de las enstas musicales de Tialia y Andalucia. A la vez. era ot ro paisaje. con mu sama de colores $y$ de ritmos totalmente diferento al de Porte Pelo y Panami. A 1 a vista estaba con su abrumachrefeeth. 11ma ensta donde "no a 1lovirlo ni a visto aotra deconsideración después del diluvin 1nivercal", como dectía un eseritor de la épnea. A harlovento de Paita, en cincaprnta leanas de costa, torlo cra arenal muerto, es decir no haldía ntrerto alenun. Ya deste en-

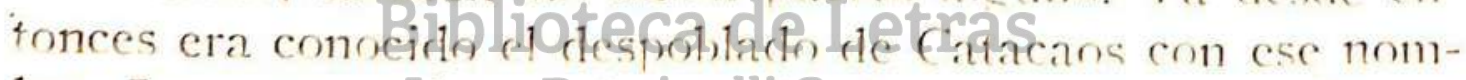

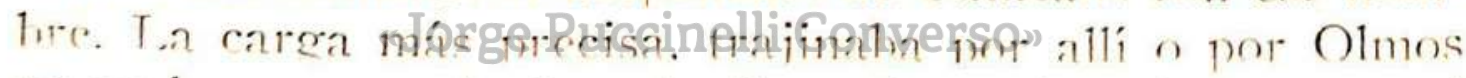
on mulas que caminahan de día v de noche sin tener dué heber ni qué comer, para salir cuanto antes de alli. Tós viajeros españoles que no podlian hacer uso de literas, morian en acturllas soledades sin caminos señalados porduce el vienin los borraba, formando cada instante rliferentes montes de arena. La única guía cran, por eso, los indios y las estrellas. Ni venta ni pozo habían sido erigidos en Catacans por-

(12) "Diario de Lima" (1640-1694). Crónica te l: Enoca colonial, por Tosephe y Franeiseo do Mugaluru, 1a. edición. Lima, 1918. (Coleceión Trteaga-Romero, 7." serie. Vol. VIT, tome T, póg. 141).

(13) "Memoria del estado del Perú por lo Real Audiencia de Lima al virrey conde de Lemos "en Pelaciones de los Virreyes y Audieneias que han gobernado el Perú", vol. II, págs. 200 y 249.

(14) Coello, Carta eit. Carta del Conde de Lemos. 
que el negocio de las literas lo hacía el corregidor de Piura y cuando un tiempo fué agregado a la cofradía del Santísimo Sacramento, se compuso el corregidor con el mayordomo.

Más al Sur de Catacaos estaba el corregimiento de Saña y Lambayeque, con un puerto, Chérrepe, de algún comercio. Alli se producia jabón y azúcar que salia para Linua en gran cantidad, asi cono cordobanes y conservas, que no tenian más gabelas que la alcabala en Lima. El correginiento de Saña era uno de aquellos donde existía el repartimiento de vino en favor de los corregidores. Compraban éstos el vino y lo vendian a los indios por el quintuplo o más, obligándoles, con su voluntad o sin ella, a beber ese licor. Con motivo de este repartimiento, se daba la paradoja de que muchos españoles eonstunieran "chicha”, la bebida tipica del pais, y muchos indios, vino. En donde no existía el repartimiento de vino, los puestos de "chicha" pagaban un tanto a los corregidores.

Avanzando hacia el sur, venía en seguida Trujillo, con dos puertos muy málos. Huancliacō nalabrigo. Embarcábase en dichos puertos harina, garbanzos, frejoles blancos y negros y otros productos, asi como aceitunas, conservas y azúcar para Panamá y Lima. A seis leguas de Trujillo estaban las haciendas de los vecinos, en el valle de Chicama, formado, como todos los valles de la costa, por los ríos provenientes de la cordillera. Tenía entonces Chicama siete legtias de largo y seis y media de ancho y era considerado el valle más ameno de América. Las grandes haciendas de españoles alternaban entonces alli con sementeras de indios, especialmente en Chocope y Santiago; pero quejábanse éstos de que ellas eran las últimas en ser regadas. El alcalde de aguas, puesto por los virreyes, vigilaba la exacta distribución del agua; y además debía haber un Pro- 
tector de indios y juez de censos, oficio que se obtenía por compra. De Chicama era de donde se sacaba el algodón del cual se hacian los pabilos que eran llevados a I ima y a los asientos mineros y los sacos en que se ponian las harinas para conducirlas por mar a Panama, Porto Belo y otras partes.

Dos pequeños puertos en dirección a I ima eran Guañape y Santa, por donde se embarcaba para esa capital harinas y legumbres. Otros pequeños puertos o caletas abastecian a Lima de carbon, de algarrobos y frutas. Lin Huanra, situada un poco más al sur, estaban las salinas que eran consideradas las mayores del mundo.

Los españoles escaseaban en todos los valles de la costa. Se consideraba ciudad grande la que tenía I, 000 a $I, 500$ vecinos de esa clase. Que una villa contase 70 casas de españoles, venía a ser motivo para darle importancia. Otros lugares eran integramente de inclios, con aislados españoles en las haciendas circundantes. Estos españoles eran, a veces, frailes con casas dedicadas a la labranza y a la ganadería. De cuandogcin cuando, èncōntrábase en los valles y en las faldas de las montañas ruinas y despoblados provenientes de la época anterior a la conquista. Los negros hacian el laboreo de las haciendas y el servicio en la ciudad, al lado de las familias señoriales; en el camino entre la capital y la cordillera ya merodeaban los "cimarrones", negros fugados y bandoleros.

\section{El Catlao}

El Callao tal vez no había superado entonces las 400 casas de españoles que le asigna una relación de principios del siglo XVII, sin contar las de indios y negros. Las calles rectas, salían al campo. En la playa se veían almacenes y 
bodegas de vino, así como el edificio de las Cajas Reales, cuyos muros lamía el mar. Habia dos fuertes y una muralla para la defensa del puerto. Gran centro comercial e importante plaza militar, el Callao era también un presidio. La dotación del presidio debía tener quinientas plazas; pero casi siempre tenía mucho menos.

Los españoles que vivian en el Callao eran generalmente empleados, proveedores y religiosos. En la clase inferior, podía distinguirse los soldados, marineros y artesanos; estos últimos eran, sobre todo, carpinteros, calafates y aserradores para la carena de galeones y demás bajeles.

Cuando no se hacían a la mar custodiando la plata que iba de Arica a Panamá en un viaje de siete a ocho meses o en busca de los enemigos, reposaban en la bahía las naves de guerra capitana y almiranfa, cada una de seiscientas toneladas y cuarenta piezas de artillería. Una galera construída en la época delevirrey conde de Chinchón servía de cárcel en la real atarazana o muelle. Veíase además, en el puerto, un patache de trescientas toneladas y diez y ocho piezas de bronce, dos chinehor ros o barcos hís pequeños y varias

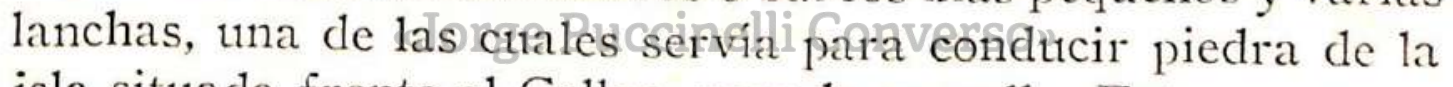
isla situada frente al Callao, para la muralla. Estos no eran, por cierto, los únicos navíos surtos permanentemente en el Callao, pues hay que mencionar todavía el vigía que zarpaba a veces en la peligrosa y larga navegación al sur de Chile, el barco que llevaba el situado de Chile y el del socorro a Valdivia.

El tráfico era considerado mt1y intenso. Llegaba a casi cincuenta navíos. De Chile se traía al Callao cueros, sebo para candelas, fruta en conserva, y hasta trigo, cuando no bastaba el del Perú. A cambio del vino y de otros artículos pertuanos, venía de Nicaragua, Guatemala y Sonsonate al Perú, brea, cochinilla, tabaco, cera amarilla, miel 
de abejas, bálsamo y palo de Mechoacin. Para Acapulco salia oro y plata y de alli venian paños finos, seclas, terciopelos, entorchados, pasamaneria, damasco, tafetanes y sedas mandarinas, provenientes de la China, más apreciadas que las de México.

El regreso de Acapulco al Callan verificábase en Octubre o Noviembre ( 15 ).

El miércoles 9 de nu, wiembre de 1607 , a las tres de la madrugada, disparo la capitana, muy distante de la isla de San Lorenzo, situada a la entrada del Callao, una pieza de artillería y a las cuatro de la mañana le respondieron del puerto con tres piezas. El vecindario de Lima despertio con este ruidn. Grande como era cl deseo de ver la recepción del nuevo virrey, fueron muchisimos los que comenzaron a ponerse en camino hacia el Callao.

A mediodía la capitand se incicercando a la isla y a las siete de la noche dió fondo en el puerto. Dispararon todos los fuertes y la nao "San riancisco Solano" que estaba surta haciendo oficio de capitana disparó más de doscientas piezas de atillería la la que traiatab virrey disparó nueve piczas.

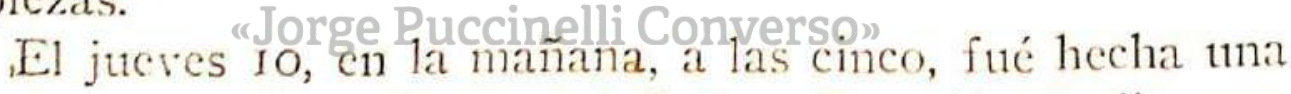
salva con toda la artillería del Callao. Pareció aquella tuna señal convenida. La muralla del puerto fué llenándose de mujeres y hombres "que parecia un jardin de flores según la varieclad de mantillas y vestidos muy costosos que se hicieron para el propósito, así de hombres como de mujeres", según cuenta bobamente Mugaburu.

JORGE BASADRE.

(15) Relación de la Audieneia al Virrey conde de Castellar, págiua 277. Ms. de Villalobos, cit. págs. 270 a 295; Riva Agüero, resumen del ms. del judío portugués (Congreso de Sevilla, 1914) pág. 364. 